\title{
A micelle mediated extraction as a new method of obtaining the infusion of Bidens tripartita
}

\author{
Karolina Śliwa ${ }^{\boxplus}$, Elżbieta Sikora', Jan Ogonowski', Jan Oszmiański² and Joanna Kolniak- \\ Ostek ${ }^{2}$
}

1 Faculty of Chemical Engineering and Technology, Cracow University of Technology, Kraków, Poland; 2 Department of Fruit, Vegetable and Grain Technology, Wrocław University of Environmental and Life Sciences, Wrocław, Poland

In this paper, the extracts of three-part beggarticks (Bidens tripartita) were prepared using ultrasonic assisted micelle-mediated extraction method (UAMME). Different kind of surfactants and WPC (whey protein concentrate) were applied. In the $B$. tripartita extracts twenty polyphenols were identified by UPLC-DAD-MS. Both aqueous and UAMME extracts mainly contained chlorogenic acid, caftaric acid and its derivatives as well as luteolin 7-Oglucoside. The luteolin was extracted with Rokanol B2 and Triton X-100. Furthermore, antioxidative properties of the extracts were analyzed with two methods: reactions with di(phenyl)-(2,4,6-trinitrophenyl)iminoazanium (DPPH) reagent and Follin's method. The DPPH radical scavenging by micellar extracts was in general comparable with the antioxidant activity of conventional extracts. The most active was sample with Tego Care CG90, reducing about $73 \%$ of the radical. Obtained results confirmed that the UAMME might be an alternative method, to the liquid-liquid or solid-liquid extraction, of obtaining specified extracts rich in active compounds. Selecting a suitable surfactant may thus provide the expected composition of the extract.

Key words: ultrasonic assisted micelle-mediated extraction, threepart beggarticks, whey protein concentrate

Received: 26 November, 2015; revised: 25 April, 2016; accepted: 18 May, 2016; available on-line: 26 May, 2016

\section{INTRODUCTION}

Three-part beggarticks (Bur-marigold, Bidens tripartita) is a perennial, branched plant from the genus Bidens, family Compositae, subfamily Asteroideae. It grows near the aquatic habitats, periodically flooded or wet. It occurs in Europe, Asia, North Africa and North America. In Poland it is found mainly in the area of Białogon on the Bobrza River, Cedzyna on the Lubrzanka River and lagoons: Kielce - Szydłówek, Cedro-Mazur, Zagórze (Szafer \& Kulczyński, 1953). The herb of three-part beggarticks was used in folk medicine as a diuretic, sudorific and anti-inflammatory agent (for review see Shikov et al., 2014). Now it is used in fever treatment, skin diseases, bladder and kidney troubles, and as an immunological system stimulant (Wolniak et al., 2007). The bur-marigold was also reported to be effective treatment for the allergic itching among children (Sezik et al., 2004). The methylene chloride extract of B. tripartita showed high activity in the inhibition of cancer L1210 (mouse leukemia) cells and against thrombin (Goun, 2002). Research by Tomczykowa and coworkers (2008) concerning antimicrobial and antifungal activity of aerial parts of $B$. tripartita fully explain the use of the flowers and herbs for treatment of mucocutaneous candidosis, as well as skin disease and inflammations caused by microbial and fungal organisms. Moreover, the essential oil obtained from the roots of $B$. tripartita exhibited a strong antifungal activity (Tomczykowa et al., 2011). Tolmacheva and coworkers (2014) examined twenty different herb extracts, from species occurring all over Eastern Europe, using two biological tests: wild-type and reporter Chromobacterium violaceum, and came to a conclusion, that only $B$. tripartita herb contains molecules that imitate acyl-homoserine lactone, operating as the agonist for bacteria 'quorum sensing' communication. The investigation on acute toxicity of an alcoholic extract of $B$. tripartita plant in mice suggested that it is relatively safe toxicologically and could be used with some degree of safety (Sandu et al., 2012). The further evaluation of water and alcoholic extracts from this plant indicated good in vivo biocompatibility in rats (Sandu et al., 2013).

Phytochemical studies of three-part beggarticks showed that this herb is a rich source of active compounds: flavones, flavanones, chalcones and aurones, coumarins, a small amount of vitamin C, carotenoids and a volatile oil. The green parts of $B$. tripartita contain polyacetylenic compounds, linoleic acid and ocimene, whereas in the flowers mainly thiophene and traces of cosmene as well as eugenol were identified (Wolniak et al., 2007; Pozharitskaya et al., 2010). The main components of the essential oil obtained from the roots of $B$. tripartita by hydrodistillation were $\alpha$-pinene, $\beta$-bisabolene, p-cymene, hexanal, linalool, p-cymene9-ol, $\beta$-elemene, 2-pentylfuran, and silphiperfol-6-ene (Tomczykowa et al., 2011). In turn, $\alpha$-pinene, p-cymene, $\beta$-ocimene, and $\beta$-elemene are predominant in extracts prepared by supercritical $\mathrm{CO}_{2}$ extraction with solid-phase trap (Kaškonienè \& Maruška, 2015).

The main flavonoid constituents of the methanol extracts were isookanin-7-O-glucoside, luteolin-7-O-glucoside and luteolin (Wolniak et al., 2007; Lv \& Zhang, 2013). The latter is especially important as the in vivo antiproliferative activities of luteolin against human breast cancer cell and prostatic cancer were proven (Huo et al., 2013).

Increased demand for safe and natural origin products is clearly visible. Therefore, scientists are elaborating safe methods of obtaining active substances. Un-

e-mail: karola@chemia.pk.edu.pl

Abbreviations: WPC, whey protein concentrate; UAMME, ultrasonic assisted micelle-mediated extraction method; DPPH, di(phenyl)-(2,4,6-trinitrophenyl)iminoazanium 
fortunately, there are still no effective methods of the separation of natural extracts rich in bioflavonoids. As the compounds are very sensitive to temperature and light, the purification deprives them of their valuable properties (Ballesteros-Gomez, 2010). A relatively new method is application of surfactants for the preparation of intermediates, containing the plant origin bioflavonoids in a high concentration.

The micelle-mediated extraction method (MME) in comparison with the liquid-liquid or solid-liquid extraction methods does not require the use of toxic organic solvents, so it offers a convenient alternative to the conventional extraction systems (Szymanowski, 2000). In this method, instead of an organic solvent, an aqueous surfactant solution is used, which solubilizes desired ingredient in the hydrophobic micelles (Paul \& Moulik, 2001). Factors, which affect the dissolving capacity of the surfactants solution, are the structure and type of surfactant, the presence of electrolytes and other organic materials and the temperature (Quina \& Hinze, 1999; Ferrera et al., 2004). This methodology offers the advantages of safety, low cost, ability to concentrate solutes and low toxicity compared to classical organic solvents (Shi et al., 2007; Zhou et al., Trivedi et al., 2011). The extracted substances can be safely used in foods, pharmaceuticals or cosmetics. The ultrasonic assisted micelle-mediated extraction (UAMME) could be applied to obtain biologically active substances, such as vitamins $A, E, K, B 1$, paracetamol or salicylic acid, from the biological material (Madej, 2009; Tomaszkiewicz-Potępa et al., 2010), and bioflavonoids from plant material (Tomaszkiewicz-Potępa et al., 2010; Śliwa et al., 2013).

UAMME method seems to be promising as a pure method to obtain B. tripartita extract, due to the rich composition of the actives and interesting raw material for cosmetic and medical application. The aim of this work was to assess four nonionic surfactants (Tego Care CG90, Sucrose Stearate, Triton X-100, Rokanol B2) as well as WPC (whey protein concentrate) in the extraction of three-part beggarticks herb (B. tripartita) by UAMME method. The composition and antioxidant properties of UAMME extracts were analyzed in comparison to water. The bioflavonoids composition was determined with UPLC-DAD-MS method. The HLB of studied surfactants as well as the surface tension of $1 \%$ solutions of the surfactants were measured, to find out an explanation for the differences in bioflavonoids concentration. Moreover, the hydrophobic properties $(\log \mathrm{P})$ of selected flavonoids were compared. In this work, probably for the first time, ultrasonic assisted micelle-mediated extraction (UAMME) method was used to separate bioactive ingredients from B. tripartita.

\section{MATERIALS AND METHODS}

Chemicals. Aluminum chloride, sodium hydroxide, sodium nitrite were obtained from POCh (Gliwice Poland). The Folin-Ciocalteau's reagent, DPPH, luteolin, gallic acid were supplied by Sigma Aldrich (Poland). Among the used surfactants there were: Rokanol B2 (Alkoxylated (EO/PO) natural alcohol C16-C18) from PCC Rokita (Poland), Triton X-100 (Octylphenol Ethoxylate (EO)) from DOW Chemicals Co. (DOW Poland), TegoCare CG 90 (Cetearyl Glucoside) from Evonik Industries (Germany) and Crodesta F160 (Sucrose Stearate) from Croda Personal Care (Croda, Poland). The $80 \%$ WPC was purchased from Bartex
(Pasłęk, Poland). B. tripartita herb was bought from Dary Natury (Grodzisk, Poland). All the used reagents were of analytical grades.

Extraction procedure. Aqueous extract. Dried threepart beggarticks herbs ( $3 \mathrm{~g})$ were exhaustively extracted with $200 \mathrm{ml}$ of distilled water. The extraction was carried out in an ultrasonic bath at room temperature, for $30 \mathrm{~min}$.

Micelle-mediated extraction. Dried three-part beggarticks herbs (3 g) were exhaustively extracted with $200 \mathrm{ml}$ of aqueous surfactant solution (1\%) or solution of 1\% WPC. Four non-ionic surfactants were used: Tego Care CG $90(\mathrm{HLB}=11)$, Sucrose Stearate $(\mathrm{HLB}=16)$, Triton X-100 $(\mathrm{HLB}=13.5)$, Rokanol B2 $(\mathrm{HLB}=6.7)$. Protein solutions were prepared by dissolving WPC in an appropriate amount of distilled water and subsequent mixing with magnetic stirrer until completely dissolved and left for protein swelling for $1 \mathrm{~h}$. In all of the cases, $0.1 \mathrm{~g}$ of sodium benzoate and $0.5 \mathrm{~g}$ of citric acid were added to the eluent solution. The extraction was carried out in an ultrasonic bath, at room temperature, for $30 \mathrm{~min}$.

Polyphenols content. The content of polyphenols in individual extracts was determined by means of the liquid chromatography (UPLC-DAD-MS) method, applied recently in Oszmiański and coworkers (2015). The identification of the polyphenols of $B$. tripartita extracts was carried out using an ACQUITY Ultra Performance LCTM system with a mass detector G2 QT of Micro-mass spectrometer equipped with an electrospray ionization (ESI) source operating in negative mode (UPLCTM; Waters Corporation, Milford, MA, USA). The separation of individual polyphenols was carried out using a UPLC BEH C18 column $(1.7 \mu \mathrm{m}$, $2.1 \times 100 \mathrm{~mm}$, Waters Corporation) at $30^{\circ} \mathrm{C}$. The elution solvents were aqueous $0.1 \%$ formic acid (A) and 100\% acetonitrile (B). Samples $(10 \mu \mathrm{l})$ were eluted according to the linear gradient described by Oszmiański and coworkers (2013). Analysis was carried out using full scan, data-dependent MS scanning from m/z 100 to 1500 . The mass tolerance was 0.001 Dalton, and the resolution was 5000 . Leucine enkephalin was used as the internal reference compound during ESI-MS accurate mass experiments and was permanently introduced via the LockSpray channel using a Hamilton pump. The lock mass correction was \pm 1000 for the mass window. All TOF-MS chromatograms are displayed as base peak intensity (BPI) chromatograms and scaled to 12400 counts per second (cps) $(=100 \%)$. The effluent was led directly to an electrospray source with a source block temperature of $130^{\circ} \mathrm{C}$, a desolvation temperature of $350^{\circ} \mathrm{C}$, a capillary voltage of $2.5 \mathrm{kV}$ and a cone voltage of $30 \mathrm{~V}$. Nitrogen was used as the desolvation gas with a flow rate of $300 \mathrm{~L} \cdot \mathrm{h}^{-1}$.

The characterization of the single components was carried out based on their retention time and the accurate molecular masses. Each compound was optimized to its estimated molecular mass $[\mathrm{M}-\mathrm{H}]^{-}$in negative mode before and after fragmentation. The data obtained from LC/MS were subsequently entered into the MassLynx 4.0 ChromaLynxTM Application Manager software. Based on the data, the software allows scanning different samples for the characterized substances.

The runs were monitored at the following wavelengths: (-)-epicatechin and procyanidin at $280 \mathrm{~nm}$, hydroxycinnamates at $320 \mathrm{~nm}$ and flavonol glycosides at $360 \mathrm{~nm}$. Retention times $\left(R_{t}\right)$ and spectra were compared with those of pure standards. Calibration curves at concentrations ranging from 0.05 to $5 \mathrm{mg} / \mathrm{ml}$ 
Table 1. Bioflavonoid composition of the obtained extracts (C - concentration in [mg/l], [\%] - part of the total flavonoid content).

\begin{tabular}{|c|c|c|c|c|c|c|c|c|c|c|c|c|}
\hline & \multicolumn{2}{|c|}{ CF-160 } & \multicolumn{2}{|c|}{ TX-100 } & \multicolumn{2}{|l|}{ RB2 } & \multicolumn{2}{|c|}{ TCCG90 } & \multicolumn{2}{|l|}{ WPC } & \multicolumn{2}{|l|}{$\mathrm{Aq}$} \\
\hline & C & {$[\%]$} & C & {$[\%]$} & C & {$[\%]$} & $\mathrm{C}$ & {$[\%]$} & C & {$[\%]$} & $\mathrm{C}$ & [\%] \\
\hline Neochlorogenic acid & 2.5 & 4 & 1.7 & 2 & 2.3 & 2 & 6.3 & 8 & 18.3 & 38 & 2.0 & 4 \\
\hline Chlorogenic acid & 30.1 & 43 & 17.8 & 23 & 25.9 & 22 & 37.0 & 46 & 13.8 & 28 & 22.4 & 42 \\
\hline Caftaric acid & 8.9 & 13 & 5.1 & 7 & 7.3 & 6 & 10.8 & 13 & 3.5 & 7 & 6.8 & 13 \\
\hline Caftaric/coutaric acid derivatives & 5.7 & 8 & 3.6 & 5 & 6.4 & 6 & 7.1 & 9 & 2.7 & 5 & 4.0 & 8 \\
\hline Cryptochlorogenic acid & 1.7 & 2 & 1.1 & 1 & 1.6 & 1 & 2.5 & 3 & 4.5 & 9 & 1.3 & 2 \\
\hline Caftaric acid derivatives & 2.1 & 3 & 1.0 & 1 & 1.7 & 1 & 3.6 & 4 & 0.7 & 1 & 1.6 & 3 \\
\hline Caffeic acid, plus terminal rhamnose & 3.6 & 5 & 1.9 & 3 & 3.1 & 3 & 5.8 & 7 & 1.3 & 3 & 2.8 & 5 \\
\hline Luteolin-3,7-dihexoside & 0.7 & 1 & 0.5 & 1 & 0.4 & 0 & 0.4 & 0 & 0.2 & 0 & 0.6 & 1 \\
\hline Quercetin-3-O-hexoside & 1.0 & 2 & 1.9 & 2 & 2.3 & 2 & 0.6 & 1 & 0.1 & 0 & 1.0 & 2 \\
\hline Quercetin-3-O-rutinoside & 0.2 & 0 & 0.4 & 1 & 0.5 & 0 & 0.1 & 0 & 0.1 & 0 & 0.2 & 0 \\
\hline Quercetin-3-O-hexoside & 0.8 & 1 & 1.1 & 1 & 1.3 & 1 & 0.5 & 1 & 0.4 & 1 & 0.7 & 1 \\
\hline Luteolin-7-O-glucoside & 6.0 & 9 & 13.5 & 18 & 16.7 & 14 & 2.8 & 3 & 1.4 & 3 & 5.0 & 9 \\
\hline Quercetin-3-O-6-acetylglucoside & 1.0 & 1 & 1.5 & 2 & 1.6 & 1 & 0.6 & 1 & 0.4 & 1 & 0.8 & 2 \\
\hline 4,5-di-O-caffeoylquinic acid & 0.2 & 0 & 1.3 & 2 & 1.6 & 1 & 0 & 0 & 0 & 0 & 0.3 & 0 \\
\hline Luteolin-3-O-hexoside & 0.1 & 0 & 0.9 & 1 & 1.1 & 1 & 0 & 0 & 0 & 0 & 0.2 & 0 \\
\hline Apigenin-glucoside & 1.3 & 2 & 4.2 & 6 & 5.4 & 5 & 0.5 & 1 & 0.3 & 1 & 1.0 & 2 \\
\hline 3,5-di-O-caffeoylquinic acid & 0.5 & 1 & 2.4 & 3 & 3.6 & 3 & 0 & 0 & 0 & 0 & 0.3 & 1 \\
\hline Luteolino -3-O -glucosyl-6"-acetate & 0 & 0 & 1.7 & 2 & 2.1 & 2 & 0.1 & 0 & 0 & 0 & 0.3 & 1 \\
\hline Quercetin-3,4-diglucoside & 0.3 & 0 & 2.9 & 4 & 7.1 & 6 & 0.9 & 1 & 0.4 & 1 & 0.1 & 0 \\
\hline Luteolin & 0 & 0 & 4.6 & 6 & 12.1 & 10 & 0 & 0 & 0 & 0 & 0 & 0 \\
\hline Total & 69.4 & & 76.0 & & 116.5 & & 81.2 & & 48.7 & & 53.4 & \\
\hline
\end{tabular}

$\left(\mathrm{R}^{2} \leq 0.9998\right)$ were made from $(-)$-epicatechin, procyanidin A2, procyanidin B2, neochlorogenic acid, caffeic acid, quercetin-3-O-galactoside, quercetin-3-O-rutinoside and kaempferol-3-O-glucoside as the standards. All incubations were done in triplicate. The results were expressed in milligrams per 1 of extracts.

In-vitro Antioxidant assay. Flavonoids content was determined using their ability to react with aluminium chloride according to the method specified by Hussain and coworkers (2012). The following procedure was applied: $1 \mathrm{ml}$ of the extract was dissolved in $1.1 \mathrm{ml}$ of distilled water. Next $0.3 \mathrm{ml}$ of $\mathrm{NaNO}_{2}$ solution (5\%) was added and left for 5 minutes. Then, $0.6 \mathrm{ml}$ of $\mathrm{AlCl}_{3}$ solution $(10 \%)$ and after $6 \mathrm{~min}, 2 \mathrm{ml}$ of $1 \mathrm{M} \mathrm{NaOH}$ were respectively added. The mixture was diluted with $0.275 \mathrm{ml}$ of distilled water and the absorbance of the sample was measured immediately, at $\lambda=510 \mathrm{~nm}$. The spectra were recorded with Macherey Nagel Nanocolor $\mathrm{UV} / \mathrm{Vis}$ spectrophotometer. A standard curve was plotted for luteolin and the result were given by luteolin equivalent, (mg/l). Because of the presence of surfactants, the obtained results were not counted to the dry weight of the extract.

Determination of polyphenols in the extracts was performed with the Folin-Ciocalteau (FC) method described in Grajka (2000) and in Cybul and Nowak (2008). Definite volume $(1 \mathrm{ml})$ of tested extract was transferred to $10 \mathrm{ml}$ volumetric flask. Next, $5 \mathrm{ml}$ of the FC reagent was added and the mixture was incubated for 4 minutes. After that, $4 \mathrm{ml}$ of $7.5 \%$ sodium carbonate solution was added. The blank sample was also prepared. The test flasks were placed in the dark and left for 2 hours. After this time, the absorbance was measured, at wavelength $\lambda=765 \mathrm{~nm}$. The results were calculated based on the content of gallic acid, using the calibration curve.

The DPPH scavenging potential was estimated as previously described by Shabir and coworkers (2011) with slight modifications. Definite volume $(2 \mathrm{ml})$ of DPPH methanol solution $(0.05 \%)$ was added to $4 \mathrm{ml}$ of each extract solution with $4 \mathrm{~cm}^{3}$ of distilled water and left to react at room temperature, in the dark, for $30 \mathrm{~min}$. The absorbance of the obtained mixtures was measured at $\lambda=517 \mathrm{~nm}$.

\section{RESULTS AND DISCUSSION}

In all prepared extracts the flavonoid compounds were identified. The results of qualitative analysis showed that the final composition of the extracts depended on the type of applied extracting agent (Table $1)$. The highest content of these compounds was obtained with used of Rokanol B2 (RB2). It should be emphasized that in this case the amount of flavonoids was twice as high as in the aqueous extract. The flavonoid content in the extracts decreased sequentially depending on the applied eluent, as followed: aqueous solution of Rokanol B2 (RB2), Tego Care CG90 (TCCG90), Triton X-100 (TX100), Crodesta F160 (CF160), pure water (Aq) and whey protein concentrate (WPC) solution. As showed in Wolniak and coworkers (2007), the methanol extract of herb contained three main flavonoids: isookanin 7 -O-glucoside $(0.16 \%)$, luteolin $7-\mathrm{O}$ glucoside $(0.18 \%)$ and luteolin $(0.031 \%$, calculated on dry weight). Using chromatography (UPLC-DAD-MS) 

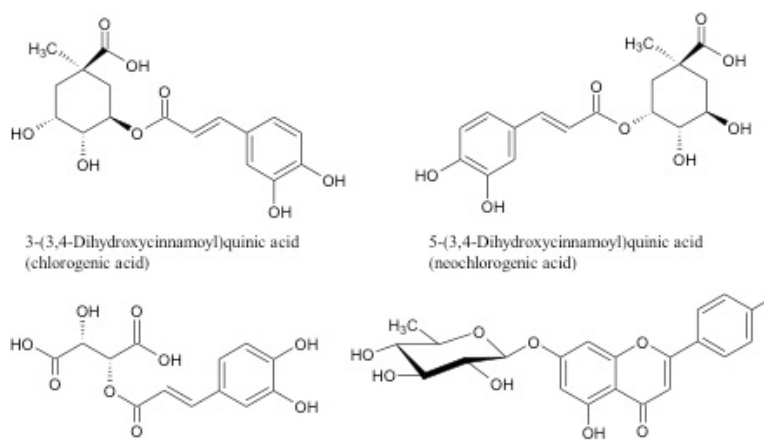

5-(3,4-Dihydroxycinnamoyl)quinic acid (heachlorogenic acid)

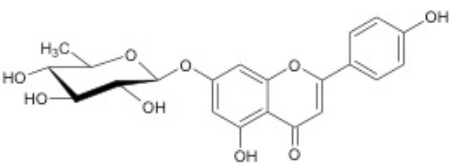

caffeyltartaric acid (caftaric acid)<smiles>O=c1cc(-c2ccc(O)c(O)c2)oc2cc(O)cc(O)c12</smiles>

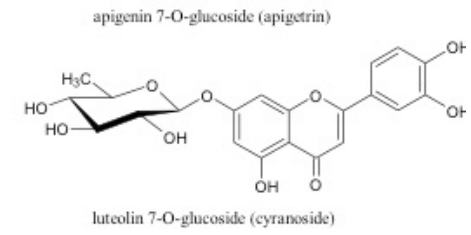

Figure 1. Phenolic compounds identified in the $B$. tripartita extracts.

method twenty polyphenols in B. tripartita extracts were identified. Both aqueous and UAMME extracts mainly contained chlorogenic acid, caftaric acid and its derivatives as well as luteolin 7-O-glucoside (Table 1, structures presented in Fig. 1), which was expected due to the polarity of the mentioned compounds. The luteolin was extracted only with Rokanol B2 and Triton X-100, from which the first one gave slightly higher yield. Using these surfactants, instead of water, three-fold more luteolin 7-O-glucoside was obtained which resulted in a significant increase, of the total flavonoids content, compared to other eluents used. The results suggested that in the case of phenolic compounds extraction, $\mathrm{RB} 2$ with mixed chain EO/PO (ethoxy/propoxy) is a better agent, although the qualitative composition of Rokanol B2 and Triton X-100 extracts was similar. It could be probably explained by the nature of the surfactants. Both of the compounds belong to a group of polyalkoxylated surface-active agents. The micelles formed by them are characterized by the presence of voids in the palisade layer.

Generally, the main component of all the UAMME extracts was chlorogenic acid. The exception was the WPC extract containing 38\% of neochlorogenic acid. The content of neochlorogenic acid was three times higher in comparison to Tego Care CG90 extract and ten times higher compared to the aqueous extraction.

The results indicate, that the differences in the efficiency of phenolic compounds extraction could be the result of different properties of the surfactants. Table 2 shows HLB values and surface tension of used

Table 2. Characteristic of the surfactants.

\begin{tabular}{lll}
\hline Surfactant & HLB $^{*}$ & Surface tension \\
\hline Rokanol B2 & 6.7 & 29.69 \\
\hline Triton X-100 & 13.5 & 28.69 \\
\hline Tego Care CG 90 & 11 & 33.20 \\
\hline Crodesta F160 & 14.5 & 33.58 \\
\hline WPC & - & 43.55 \\
\hline
\end{tabular}

*Based on the manufacturer's data sheet; ${ }^{* *}$ Average of five measurements
Table 3. The hydrophobic properties $\left(\log \mathrm{P}^{*}\right)$ of selected flavonoids.

\begin{tabular}{lc}
\hline Flavonoid & $\log \mathrm{P}$ \\
\hline Neochlorogenic acid & -0.4 \\
\hline Chlorogenic acid & -0.4 \\
\hline Apigenin-glucoside & -0.1 \\
\hline Caftaric acid & 0.1 \\
\hline Quercetin-3-O-6-acetylglucoside & 0.4 \\
\hline Luteolin-7-O-glucoside & 0.5 \\
\hline Luteolin & 1.4 \\
\hline
\end{tabular}

*Computed value (XLOGP3-AA)

surfactants. Among the studied compounds, Rokanol B2 was the most hydrophobic $(\mathrm{HLB}=6.7)$ and caused higher decrease of the water surface tension. Perhaps this is the main reason for its best efficiency. However, relationship between the HLB value or surface tension and the high content of the particular flavonoids was not found. Finding the correlation requires further studies. There is also no evident relationship between the hydrophobic properties of the flavonoids (Table 3) and their concentration in the obtained extracts.

Table 4 shows the results of the determination of antioxidant properties of the obtained extracts. All of the results are the average of three measurements. Results obtained with qualitative method confirmed the higher content of flavonoids in extracts prepared according to the UAMME method. Incompatibility with chromatographic analyses can be explained by closing of the antioxidant substances inside of the micelles. A similar effect was observed by Guo and coworkers (2007) for Triton X-100. The DPPH radical scavenging by micellar extracts was generally comparable with the activity of conventional extracts. The most active was sample with Tego Care CG90, reducing ca. $73 \%$ of the radical. The highest activity of the extract suggests that other active compounds are also present in the mixture, and that antioxidative synergism may occur. This effect was also indicated by Wolniak and coworkers (2007). The advantages of UAMME were revealed by the comparison of the aqueous extract obtained by sonication at room temperature (blank experiment) and treated with boiling water (Table 4). The addition of the surfactant resulted in four- to thirteen-fold increase in the activity of the extracts.

\section{CONCLUSION}

In this paper authors performed detailed analysis of the flavonoids content in the extracts from B.tripartita obtained by UAMME method. The total flavonoids and polyphenols content in the UAMME-extracts was higher than that obtained by water extract. Moreover, the results proved that WPC could be an effective agent for UAMME extraction, similar to typical surfactants. WPC solution, as the source of micelles, might be convenient method for the preparation of plant extracts rich in natural antioxidants, as well as an alternative for common methods. Additionally, it should also be emphasized that the UAMME extracts do not contain or- 
Table 4. Characteristics of UAMME, water, methanol:water and aceton:water extracts of B. tripartite.

\begin{tabular}{|c|c|c|c|c|}
\hline Surfactant & $\begin{array}{l}\text { Concentration of } \\
\text { surfactant [\%] }\end{array}$ & $\begin{array}{l}\text { Flavonoids content per lute- } \\
\text { olin }\left[\mathrm{mg} / \mathrm{dm}^{3}\right]\end{array}$ & $\begin{array}{l}\text { Antioxidant activity } \\
{[\%]^{* *}}\end{array}$ & $\begin{array}{l}\text { Polyphenols content per } \\
\text { gallic acid }\left[\mathrm{mg} / \mathrm{dm}^{3}\right]\end{array}$ \\
\hline Rokanol B2 & 1 & 48.7 & 32.4 & 72.7 \\
\hline Triton X-100 & 1 & 31.6 & 26.7 & 75.4 \\
\hline Tego Care CG 90 & 1 & 68.3 & 72.8 & 43.1 \\
\hline Crodesta F160 & 1 & 33.2 & 23.0 & 29.8 \\
\hline WPC & 1 & 64.5 & 21.8 & 66.9 \\
\hline water* & - & 25.6 & $5.4\left(35^{* * *}\right)$ & 34 \\
\hline methanol:water ${ }^{* * *}$ & - & - & 34 & - \\
\hline acetone:water ${ }^{* * *}$ & - & - & 56 & - \\
\hline
\end{tabular}

*Demineralized water extract was used as a reference sample; **The ability to inhibit the oxidation reaction of DPPH; ${ }^{* *}$ DPPH radical scavenging activities of extracts from B. tripartite herb determined by Wolniak et al., 2007

ganic solvents and can be directly used in e.g. cosmetic compositions, also as the source of whey proteins.

The selection of a suitable surfactant may thus provide the expected composition of extract. This will be the subject of further studies.

\section{Acknowledgements}

This work was supported by Ministry of Science and Higher Education, project no. C-2/332/2014/DS-M

\section{REFERENCE}

Ballesteros-Gomez A, Sicilia MD, Rubio S (2010) Supramolecular solvents in the extraction of organic compounds, A review, Analytica Chimica Acta 677: 108-130. http://dx.doi.org/10.1016/j. aca.2010.07.027.

Huo CH, Li Y, Zhang ML, Wang YF, Zhang Q, Qin F, Shi QW, Kiyota H (2013) Cytotoxic flavonoids from the flowers of Achillea millefolium. Chem Nat Compd 48: 958-962. http://dx.doi.org/10.1007/ s10600-013-0438-y.

Cybul M, Nowak R (2008) Review of the methods applied to measuring of antioxidant plant extracts. Herba Polonica 54: 68-78 (in Polish).

Ferrera ZS, Sanz CP, Santana CM, Santana Rodriguez JJ (2004) The use of micellar systems in the extraction and pre-concentration of organic pollutants in environmental samples. Trends Analyt Chem 7: 469-479. http://dx.doi.org/10.1016/S0165-9936(04)00732-0.

Goun EA, Petrichenko VM, Solodnikov SU, Suhinina TV, Kline MA Cunningham G, Nguyen C, Miles H (2002) Anticancer and antithrombin activity of Russian plants. J Ethnopharmacol 81: 337-342. http://dx.doi.org/10.1016/S0378-8741(02)00116-2.

Grajka W (2000) Antioxidants in food. pp 219-560, Wyd. Naukowo Techniczne, Warszawa (in Polish).

Guo R, Wei P, Liu W (2007) Combined antioxidant effects of rutin and Vitamin $\mathrm{C}$ in Triton X-100 micelles. I Phar Biomed Anal 43: 1580-1586. http://dx.doi.org/10.1016/j.jpba.2006.11.029.

Hussain M, Fareed S, Ali M, Rahman M (2012) Phytochemical investigation and hyphenated chromatographic analysis of bioactive lupeol and stigmasterol in Sespadula by validated high-performance thin laver chromatography method. I Nat Pharm 3: 46-5.

Kaškoniene V, Maruška A (2015) Investigation of recovery of volatiles of Bidens tripartita L. using solid-phase extraction trap in supercritical fluid extraction. Acta Chim Slov 62: 1-7. http://dx.doi. org/10.17344/acsi.2014.260.

Lv J, Zhang L (2013) Flavonoids and polyacetylenes from the aerial parts of Bidens tripartite. Biochem Sys Ecol 48: 42-44. http://dx.doi. org/10.1016/j.bse.2012.11.016.

Madej K. (2009) Microwave-assisted and cloud-point extraction in determination of drugs and other bioactive compounds. Trends Anal Chem 28: 436-446. http://dx.doi.org/10.1016/j.trac.2009.02.002.

Oszmiański J, Kolniak-Ostek J, Biernat A (2015) The content of phenolic compounds in leaf tissues of Aesculus glabra and Aesculus parviflora walt. Molecules 20: 2176-2189. http://dx.doi.org/10.3390/molecules20022176.
Oszmiański J, Kolniak-Ostek J, Wojdyło A (2013) Application of ultra performance liquid chromatography-photodiode detector-quadrupole/time of flight-mass spectrometry (UPLC-PDA-Q/TOF-MS) method for the characterization of phenolic compounds of Lepidium sativum L. sprouts. Eur Food Res Technol 236: 699-706. http://dx.doi. org/10.1007/s00217-013-1925-x.

Paul BK, Moulik SP (2001) Uses and applications of microemulsions. Curr Sci India 80: 990-1001.

Pozharitskaya ON, Shikov AN, Makarova MN, Kosman VM, Faustova NM, Tesakova SV, Makarov VG, Galambosi B (2010) Anti-inflammatory activity of a HPLC-fingerprinted aqueous infusion of aerial part of Bidens tripartita L. Phytomedicine 17: 463-468. http://dx.doi. org/10.1016/j.phymed.2009.08.001.

Sandu RB, Tarţău L, Miron A, Zagnat M, Ghiciuc CM, Lupuşoru CE (2012) Experimental researches on acute toxicity of a Bidens tripartita extract in mice - preliminary investigations. Rev Med Chir Soc Med Nat Iasi. 116: 1230-1234.

Sandu RB, Tarţău L, Miron A, Zagnat M, Ghiciuc CM, Lupuşoru CE (2013) In vivo biocompatibility evaluation of some Bidens tripartita extracts in rats. Rev Med Chir Soc Med Nat Iasi. 117: 795-800.

Sezik E, Yesilada E, Shadidoyatow H, Kulivey Z, Nigmatullaev AM, Aripov HN, Takaishi Y, Takeda Y, Honda G (2004) Folk medicine in Uzbekistan. I. Toshkent, Djizzax, and Samarqand provinces. J Ethnopharmacol 92: 197-207. http://dx.doi.org/10.1016/j. jep.2004.02.016.

Shabir G, Anwar F, Sultana B, Khalid ZM, Afzal M, Khan QM, Ashrafuzzaman M (2011) Antioxidant and antimicrobial attributes and phenolics of different solvent extracts from leaves, flowers and bark of gold mohar (Delonix regia (Bojer ex Hook.) Raf.). Molecules 16: 7302-7319. http://dx.doi.org/10.3390/molecules16097302

Shi Z, Zhu X, Zhang H (2007) Micelle-mediated extraction and cloud point preconcentration for the analysis of aesculin and aesculetin in Cortex fraxini by HPLC. J Pharm Biomed Anal 44: 867-873. http:// dx.doi.org/10.1016/j.jpba.2007.03.035.

Shikov AN, Pozharitskaya ON, Makarova VG, Wagner H, Verpoorte R, Heinrich M (2014) Medicinal Plants of the Russian Pharmacopoeia; their history and applications. I Ethnopharmacol 154: 481-536. http://dx.doi.org/10.1016/j.jep.2014.04.007.

Szafer W, Kulczyński S (1953) Polish plants. PWN, Warszawa (in Polish).

Szymanowski J (2000) Surfactant enhanced non-classical extraction. J Radioanal Nucl Chem 246: 635-642. http://dx.doi. org/10.1023/A:1006735628794.

Śliwa K, Tomaszkiewicz-Potepa A, Sikora E, Ogonowski J (2013) Micelle-mediated extraction of elderberry blossom by whey protein and naturally-derived surfactants. Acta Bioch Pol 60: 803-806.

Tolmacheva AA, Rogozhin EA, Deryabin DG (2014) Antibacterial and quorum sensing regulatory activities of some traditional Eastern-European medicinal plants. Acta Pharm 64: 173-186.

Tomaszkiewicz-Potępa A, Śliwa K, Śliwa P (2010) Possibilities of using surface-active agents to the extraction of active ingredients of the plant material. Czasopismo Techniczne 1-Ch: 343-352 (in Polish).

Tomczykowa M, Tomczyk M, Jakoniuk P, Tryniszewska E (2008) Antimicrobial and antifungal activities of the extracts and essential oils of Bidens tripartite. Folia Hist Cytobiol 46: 389-393. http://dx.doi. org/10.2478/v10042-008-0082-8.

Tomczykowa M, Leszczyńska K, Tomczyk M, Tryniszewska E, Kalemba D (2011) Composition of the essential oil of Bidens tripartita L. 
roots and its antibacterial and antifungal activities. I Med Food. 14: 428-433. http://dx.doi.org/10.1089/jmf.2010.0066.

Trivedi P, Singh R, Shanker K (2011) Micellar extraction and cloudpoint preconcentration of labdane diterpenoids from Andrographis paniculata. J Liq Chromatogr Rel Techn 34: 2085-2102. http://dx.doi.or $\mathrm{g} / 10.1080 / 10826076.2011 .585480$.

Quina FH, Hinze WL (1999) Sufractant-Mediated Cloud Point Extractions: An Environmentally Benign Alternative Separation Approach. Ind Eng Chem Res 38: 4150-4168. http://dx.doi. org/10.1021/ie980389n.
Wolniak M, Tomczykowa M, Tomczyk M, Gudej J, Wawer I (2007) Antioxidant activity of extracts and flavonoids from Bidens tripartite. Acta Pol Pharm 63: 441-447.

Zhou J, Sun XL, Wang WS (2008) Micelle-mediated extraction and cloud point preconcentration of osthole and imperatorin from Cnidium monnieri with analysis by high performance liquid chromatography. J Chromatogr A 1200: 93-99. http://dx.doi.org/10.1093/chromsci/bmt088. 